\title{
TEMPORAL ANALYSIS OF GOALS SCORED IN FUTSAL: A COMPARISON OF TWO MODELS
}

original paper

() Wroclaw University of Health and Sport Sciences

DOI: https://doi.org/10.5114/hm.2022.108319

\section{GUILHERME ARMANDO DE MORAES ${ }^{1 \oplus}{ }^{\circledR}$, VINICIUS NAGY SOARES ${ }^{2 \oplus}$, JOÃO GUILHERME CREN CHIMINAZZO ${ }^{1 \oplus}$}

${ }^{1}$ Group for the Study of Football and Futsal, UniEduK, Jaguariúna, Brazil

${ }^{2}$ Faculty of Medical Science, State University of Campinas, Campinas, Brazil

\begin{abstract}
Purpose. In futsal, the goal is the most important situation that can lead the teams to victory. The understanding of when they are scored can help adopting effective strategies, increasing the chances of victory. This study aimed to compare 2 models for analysing goals scored in futsal as a function of time.

Methods. Overall, 1122 goals were analysed in 194 matches of the 2018 Brazilian Futsal League, male adult category. The playing time was divided into four 10-minute periods (conventional model) and eight 5-minute periods (alternative model). The goal occurrence was compared with mixed models of repeated measures, and the fit of models by Akaike information criterion (AIC) and Bayesian information criterion (BIC).

Results. Both models were statistically significant $(p<0.001)$, indicating that the means of goals were different depending on the periods. The conventional model showed that the mean of goals was higher in the final 10 minutes $(p<0.001)$; the alternative model implied that from the seventh to the eighth period the mean of goals increased by $39.1 \%$ (95\% CI: $0.27-0.64$, $p<0.001$ ). In addition, the 5 -minute model revealed a better fit than the 10 -minute model in accordance with AIC and BIC. Conclusions. This finding suggests that more reliable models are useful for better understanding of how the frequency of crucial events, such as goals, changes in the course of a match. We provide information for the coaching staff to strategically think about the best situations for their teams to succeed in competitive matches.
\end{abstract}

Key words: team sports, scoring distribution, situational variable, match period, game modelling

\section{Introduction}

Futsal is characterized by high-intensity efforts in a short interval with few pauses for recovery during the match [1-3], increasing fatigue, and decreasing athletic performance $[4,5]$. In this context, unlimited substitutions are crucial, as fatigued players can be replaced for recovery, which keeps the team in better physical and technical playing conditions [6]. Managing the moments of entrance and exit in the match is an important task because futsal is sensitive to strategic decisions, in which small adjustments can reach different results.

The goal is the main event of the match and all teams aim to achieve a positive balance between scored and conceded goals [7]. Considering that the goal frequency is not linear during the match, the characteristics of goal moments are becoming a topic of interest for the scientific community [3, 8]. Identifying patterns is essential for adopting more effective strategies, increasing the chances of victory [9]. These strategies involve not only physical and tactical aspects, but also cognitive and emotional performance. There is evidence that defensive action and organization [10], finishing action [11], and counterattacks [12] can directly influence the final result of the match.

To understand the goal frequency in futsal, several studies divided the playing time into four 10-minute periods $[13,14]$ and, as far as we know, only one study divided the playing time into 5-minute periods [15].

Correspondence address: João Guilherme Cren Chiminazzo, Grupo de Estudos em Futebol e Futsal, UniEduK, Rua Amazonas, 504, Jardim Dom Bosco, CEP: 13820-000, Jaguariúna-SP, Brazil; e-mail: chiminazzo@hotmail.com, https://orcid.org/0000-0002-0185-3262

Received: September 16, 2020

Accepted for publication: April 8, 2021

Citation: De Moraes GA, Soares VN, Chiminazzo JGC. Temporal analysis of goals scored in futsal: a comparison of two models. Hum Mov. 2022;23(4):63-69; doi: https://doi.org/10.5114/hm.2022.108319. 
Although Castagna et al. [4] argue that in futsal the average playing time per substitution is 10 minutes, the 10-minute model seems to be limited because it generalizes different situations in the same analysis category owing to the large amplitude of each period. This limitation can reduce the ability to understand game scenarios, making it necessary to adopt criteria that increase the descriptive potential of critical events that occur throughout the match $[16,17]$. However, Ohmuro et al. [18] suggest that because of the increased intensity of a futsal match, the substitution playing time reduced to 4.6 minutes. Given these scenarios, there is a need to understand which is the best option to analyse the frequency of goals in futsal (10 minutes vs. 5 minutes).

Considering this, we propose to analyse an alternative model of goal frequency in futsal matches, involving 3 criteria: theoretical validity, practical application, and statistical support. We hypothesized that an analysis of goal frequency in shorter periods (i.e., 5 minutes) might be more sensitive when compared with the conventional model. Thus, this study aimed to compare 2 models for analysing goals scored in futsal as a function of time.

\section{Material and methods}

We analysed 1122 goals that occurred in 194 matches of the 2018 Brazilian Futsal League, adult male category. The data were collected through digital summaries of the matches, available on the official website of the Brazilian Futsal League [19], transcribed to an electronic spreadsheet. The playing time was divided into four 10-minute periods (conventional model) and eight 5-minute periods (alternative model), totalling 40 minutes, in accordance with the official rules of futsal. Goals that occurred overtime were not considered (only $2.6 \%$ of the matches had overtime, during the playoffs, in line with the championship rules).

The mean and standard deviation were used as measures of central tendency and dispersion, respectively. The Shapiro-Wilk and Levene tests served to identify normality and homogeneity, respectively. The occurrence of goals was compared by using mixed models of repeated measures, with time considered as a fixed factor, and the match as a random factor. In mixed models, paired comparisons were performed to identify differences in relation to the specific periods of the match. The models were compared by using the Akaike information criterion (AIC) and Bayesian information criterion (BIC), considering the same covar- iance matrices in both models. The statistical software applied was IBM SPSS for Windows, version 25.0. We adopted $5 \%$ as the level of statistical significance.

\section{Ethical approval}

The conducted research is not related to either human or animal use.

\section{Results}

The 2018 Brazilian Futsal League was played by 19 teams from different regions. Most goals occurred in the second halves of the matches. Figure 1 shows the occurrence of goals according to the conventional model. Considering 10-minute periods, $19.3 \%$ of the goals occurred in the first period, $24.5 \%$ in the second, $22.8 \%$ in the third, and $33.4 \%$ in the final period. The mixed model of repeated measures was statistically significant $(F=14.1, p<0.001)$, indicating that the mean of goals was different depending on the match periods. The mean of goals increased from the first to the second period ( $\Delta=21.5 \%, 95 \%$ CI: $0.03-0.26$, $p=0.010)$. The last period presented greater values when compared with the previous 3 periods (first: $\Delta=42.4 \%$, 95\% CI: $0.27-0.52, p<0.001$; second: $\Delta=26.7 \%, 95 \%$ CI: $0.12-0.38, p<0.001$; third: $\Delta=$ $31.7 \%$, 95\% CI: 0.17-0.42, $p<0.001)$.

Figure 2 shows the occurrence of goals in the alternative model. Considering 5-minute periods, $9.5 \%$ of the goals occurred in the first period, $9.8 \%$ in the second, $10.8 \%$ in the third, $13.7 \%$ in the fourth, $12.9 \%$ in the fifth, $9.9 \%$ in the sixth, $12.7 \%$ in the seventh, and $20.8 \%$ in the last period of matches.

The mixed model of repeated measures was statistically significant $(F=9.2, p<0.001)$, demonstrating that the mean of goals scored in each period was different. The number of goals increased in the fourth period compared with the first $(\Delta=31.2 \%, 95 \%$ CI: $0.08-0.40, p=0.004)$, the second $(\Delta=28.6 \%, 95 \%$ CI: $0.06-0.38, p=0.007)$, and the sixth periods $(\Delta=$ $27.9 \%, 95 \%$ CI: $0.06-0.37, p=0.008$ ). The fifth period mean was higher than that in the first $(\Delta=26.9 \%$, $95 \%$ CI: $0.03-0.36, p=0.020)$, the second $(\Delta=24.1 \%$, $95 \%$ CI: $0.01-0.33, p=0.034)$, and the sixth intervals $(\Delta=23.4 \%, 95 \%$ CI: $0.01-0.33, p=0.038)$. The seventh period value was also higher compared with the first ( $\Delta=25.3 \%$, 95\% CI: 0.02-0.33, $p=0.024)$, the second $(\Delta=22.5 \%, 95 \%$ CI: $0.01-0.31, p=0.041)$, and the sixth periods $(\Delta=21.8 \%, 95 \%$ CI: $0.01-0.30$, $p=0.047$ ). Finally, the mean of goals in the final 5 minutes was higher than in all other periods (first: $\Delta=54.5 \%$, 


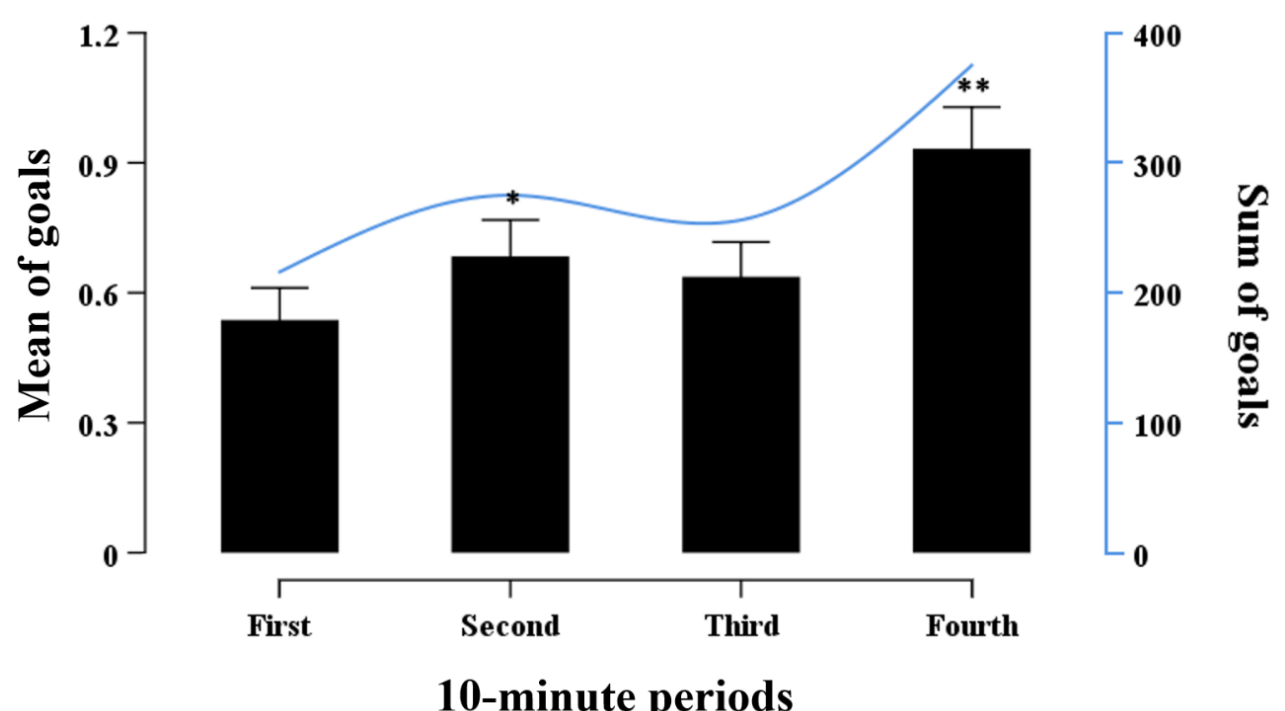

* difference $(p<0.05)$ from the first period, ${ }^{* *}$ difference $(p<0.05)$ from all periods

Figure 1. Mean and standard deviation of goals per match and sum of goals in the 2018 Brazilian Futsal League.

In the conventional model, the playing time was divided into 10 -minute periods

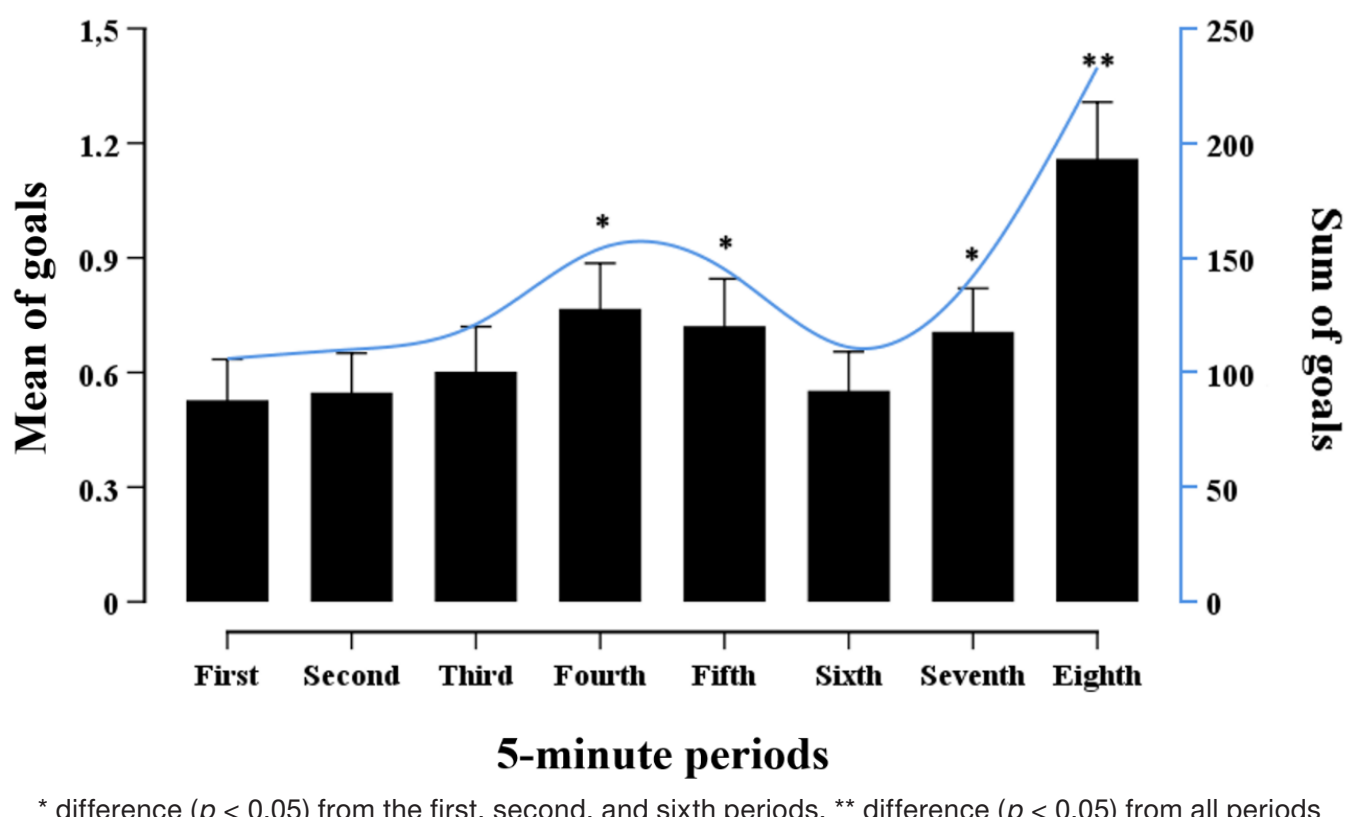

Figure 2. Mean and standard deviation of goals per match and sum of goals in the 2018 Brazilian Futsal League. In the alternative model, the playing time was divided into 5-minute periods

95\% CI: $0.45-0.81, p<0.001$; second: $\Delta=52.8 \%$, 95\% CI: $0.43-0.79, p<0.001$; third: $\Delta=48.1 \%, 95 \%$ CI: $0.37-0.75, p<0.001$; fourth: $\Delta=33.9 \%, 95 \% \mathrm{CI}$ : $0.20-0.58, p<0.001$; fifth: $\Delta=37.8 \%, 95 \%$ CI: $0.24-$ $0.63, p<0.001$; sixth: $\Delta=52.4 \%, 95 \%$ CI: $0.43-0.77$, $p<0.001$; seventh: $\Delta=39.1 \%, 95 \%$ CI: $0.27-0.64$, $p<0.001)$.

AIC and BIC are presented in Table 1. Both coefficients were lower in the 5-minute periods, suggesting that the alternative model showed a better fit compared with the conventional one.
Table 1. Akaike (AIC) and Bayesian (BIC) information criteria corresponding to the mixed models of repeated measures

\begin{tabular}{lcc}
\hline Models & AIC & BIC \\
\hline Conventional (10-minute periods) & 4053.702 & 4075.223 \\
Alternative (5-minute periods) & 4022.295 & 4065.317 \\
\hline
\end{tabular}




\section{Discussion}

Comparing 2 models of goal frequency in futsal as a function of time, we observed that dividing the playing time into shorter periods resulted in theoretical and statistical gains. Although the distribution curves are similar, the alternative model allows to understand the match with more detail, while the conventional model generalizes situations owing to wide intervals in its composition. Below, we present the theoretical validity, practical application, and statistical fit that supported the choice of the best model.

\section{Theoretical validity}

We propose that theoretical validity consists of the ability to explain the futsal match on the basis of scientific evidence and inferences from other sports with similar characteristics, such as soccer. The conventional model indicates that there is a higher occurrence of goals in the final minutes of each half, which was corroborated by the alternative model. However, the alternative model shows that the frequency of goals remains constant for 15 minutes with an increase in the final 5 minutes of the first half. As presented in other studies $[13,15]$, there is a higher goal occurrence in the final 10 minutes of the match, but we demonstrated that the mean increases by approximately $40 \%$ in the final 5 minutes, indicating that this shorter period is critical for the final result. Souza and Santana [13] attributed the number of goals increased in the last period to the rotation with the goalkeeper, which can benefit the attack owing to a special situation (i.e., $5 \times 4$ ), but also leave the defensive system more vulnerable. Shyodi Fukuda and de Santana [14] also observed a higher prevalence of goals in the final 10 minutes (37\%) and emphasized that the goalkeeper rotation was associated with positive effects because this special situation usually happened when teams were losing.

We could attribute this result to physical fatigue in the last period, but all teams are affected by drops in physical and cognitive performance, which can be mitigated by unlimited substitutions. Factors such as home advantage and mental fatigue, although influencing sports performance [20-22], do not seem sensitive in explaining the occurrence of goals in the last period. We believe that the higher goal occurrence is determined by circumstantial issues of the match, in which teams that are losing tend to adopt riskier strategies. In the final minutes, these teams generally implement a more vulnerable defensive system to create a numerical advantage in the opponent's field through goalkeeper rotation. We believe that this special situation indicates an inflection point in the occurrence of goals, which remains constant for most of the time, with a large increase in the eighth period.

Furthermore, the alternative model allows to identify a high prevalence of goals immediately after the half-time, which was not observed in the conventional model. The half-time is important for athletes' recovery, but this passive pause affects physical and cognitive performance [23, 24]. Studies have shown that at the beginning of the second half, the physical performance decreases by approximately $10 \%[23,25,26]$. Thus, it is clear that the high prevalence of goals at the beginning of the second half may be associated with insufficient physical recovery and decreased attentional capacity during the rest period, which will need to be investigated in future studies.

Considering that futsal is a timed game, in which every second can determine success or failure, an analysis of goals in 5-minute periods should be more interesting than that in 10-minute intervals. Measuring game indicators in 10-minute periods appears inappropriate, as the substitution playing time ranges from 10 minutes [4] to 4.6 minutes [18].

\section{Practical applications}

We propose that the most accurate model provides options for decision-making during the match. The alternative model shows hidden events to coaches and athletes, allowing to rethink training and game strategies, like Szwarc and Oszmaniec [27] did when creating a model to understand goalkeepers' actions. Considering the high frequency of goals at the end of the match, a strategy could be to leave the best athletes in good athletic conditions for the final 5 minutes. However, the last period is dependent on previous decisions and tends to be more unpredictable than the rest of the match. It does not seem coherent to elaborate the game strategy only on the basis of the final 5 minutes because the last period may not be enough to reverse a disadvantage in the match. Moreover, success in the previous minutes may cause teams to adopt more cautious strategies, exploring the opponents' vulnerability through counterattack. Although crucial for the final result, the last 5 minutes are dependent on the rest of the match and should not be analysed in isolation. Therefore, we cannot say whether the better strategy is to leave the best players for the end of the game or to use them to get an advantage quickly.

Another contribution of the present study concerns the understanding of the game as a non-linear phenom- 
enon, which is a concept few explored, and it is directly related to the training method. It has been demonstrated that non-linear pedagogy training programs are associated with improvements of technical-tactical behaviours of youngsters [28] and are replicable in highperformance settings. The high frequency of goals in the last period suggests that it is not enough to start the game in good conditions; it is necessary to reflect on how the players finish their matches, especially in relation to emotional and cognitive aspects. For this, mental training is important because the frustration and the perception of the game stimuli can modulate unfavourable emotional responses, reducing decision-making ability [29].

Another crucial point was the large number of goals right after the half-time break. In this context, we recommend re-warm-up as a way to prepare athletes for the second half [30,31], mitigating the consequences of inactivity during the half-time.

\section{Statistical support}

Statistical support was deliberately placed as the last criterion, not because it is less important, but because it requires some reflections. Statistical significance is a controversial issue in the scientific literature, especially in relation to the $p$-value [32]. Many studies base their conclusions on the $p$-value, attributing excessive weight to this statistical parameter, which should be analysed together with theoretical plausibility, mechanisms of action, study design, and implications in the real-world practice [32]. Even the $5 \%$ cut-off point is being debated and a more rigid threshold of $0.5 \%$ is being proposed [33]. Statistical significance is influenced by several factors, such as the number of observation units, the statistical test used, and the method adopted [32, 33]. The simple observation of more periods with statistical significance does not determine the superiority of the alternative model compared with the conventional model because the former one involves more comparison groups, which should be interpreted as a bias. In other words, the superiority of the alternative model consists not in statistical significance, but in reducing the uncertainty about the occurrence of goals in futsal. Furthermore, the comparison of 8 periods may be problematic for small samples.

We emphasize that a model is an approximation of reality, and it is not appropriate to call it true or false. Since models are inaccurate by nature, we recommend the adoption of techniques that allow a comparison of different models, such as AIC and BIC. Among so many features, AIC and BIC are based on likelihood, can be applied in different sample sizes, serve to compare multiple models, and allow the researcher to have autonomy in the choice that will be made, showing the best adjusted option (i.e., lower AIC and BIC values) [34].

Considering the statistical criteria adopted, the theoretical assumptions, and the practical importance of the results, we can affirm that the alternative model was better when compared with the conventional model.

\section{Limitations}

The present study analysed a single futsal season. Despite this, the results corroborate the current literature, indicating that our interpretations have external validity. Factors such as shots on goal, passes, and fouls were not considered and would allow a more accurate interpretation of match events. Goals scored after regulation time were not taken into account in the study, but we believe that this limitation does not compromise our conclusions since the overtime occurred only in the final matches of the season. Furthermore, we recommend that these goals should not be included in the final period of the game so that the prevalence of goals at the end of the match is not overestimated.

\section{Conclusions}

The alternative model, which divided the playing time into 5-minute periods, proved to be more reliable than the conventional model. We have demonstrated that the adoption of shorter periods allows a more detailed description of goal occurrences, while the conventional model has greater potential for producing misleading conclusions. In addition, we proposed that the comparison of models should involve 3 criteria, such as theoretical validity, practical applications, and statistical support, which can be used in future studies and in different sports.

\section{Acknowledgements}

Vinicius Nagy Soares is supported by Brazilian fellowship from Coordination for the Improvement of Higher Education Personnel (CAPES), Process No. 88882.435438/2019-01.

\section{Disclosure statement}

No author has any financial interest or received any financial benefit from this research.

\section{Conflict of interest}

The authors state no conflict of interest. 


\section{References}

1. Caetano FG, de Oliveira MJ, Marche AL, Nakamura FY, Cunha SA, Moura FA. Characterization of the sprint and repeated-sprint sequences performed by professional futsal players, according to playing position, during official matches. J Appl Biomech. 2015;31(6): 423-429; doi: 10.1123/jab.2014-0159.

2. Naser N, Ali A, Macadam P. Physical and physiological demands of futsal. J Exerc Sci Fit. 2017;15(2):76-80; doi: 10.1016/j.jesf.2017.09.001.

3. Agras H, Ferragut C, Abraldes JA. Match analysis in futsal: a systematic review. Int J Perform Anal Sport. 2016;16(2):652-686; doi: 10.1080/24748668.2016.11 868915 .

4. Castagna C, D’Ottavio S, Vera JG, Barbero Álvarez JC. Match demands of professional futsal: a case study. J Sci Med Sport. 2009;12(4):490-494; doi: 10.1016/j. jsams.2008.02.001.

5. De Oliveira Bueno MJ, Caetano FG, Costa Pereira TJ, De Souza NM, Damasceno Moreira G, Nakamura FY, et al. Analysis of the distance covered by Brazilian professional futsal players during official matches. Sports Biomech.2014;13(3):230-240; doi:10.1080/14763141. 2014.958872.

6. Milanez VF, De Oliveira Bueno MJ, Caetano FG, Chierotti P, Franzoi De Moraes SM, Arruda Moura F. Relationship between number of substitutions, running performance and passing during under-17 and adult official futsal matches. Int J Perform Anal Sport. 2020; 20(3):470-482; doi: 10.1080/24748668.2020.1761673.

7. Michailidis Y, Michailidis C, Primpa E. Analysis of goals scored in European Championship 2012. J Hum Sport Exerc. 2013;8(2):367-375; doi: 10.4100/jhse.2012.82.05.

8. Yiannakos A, Armatas V. Evaluation of the goal scoring patterns in European Championship in Portugal 2004. Int J Perform Anal Sport. 2006;6(1):178-188; doi: $10.1080 / 24748668.2006 .11868366$.

9. Gonçalves MC. Analysis of goals in the second phase of Futsal League 2013 [in Portuguese]. Rev Bras Futsal Futebol. 2015;7(24):153-157.

10. Miloski B, Pinho JP, Gobo de Freitas C, Rebouças Marcelino P, Schultz de Arruda AF. Which technical-tactical actions performed in futsal matches can discriminate the result of winning or defeat? [in Portuguese]. Rev Bras Educ Fis Esporte. 2014;28(2):203-209; doi: 10.1590/1807-55092014000200203.

11. Leite WSS. Determination of offensive coefficients in high performance futsal. Serb J Sports Sci. 2013;7(4): 167-172.

12. Marchi R, Silva C, Scramin L, Teixeira A, Chiminazzo J. Impact of goals resulting from the counter-attack of futsal team [in Portuguese]. Conexões. 2010;8(3):1622; doi: 10.20396/conex.v8i3.8637724.

13. Souza NM, Santana WC. Analysis of the goals in futsal league games: comparison between the seasons 2013, 2014 and 2015 [in Portuguese]. Motricidade. 2018;14(S1): 134-141.
14. Shyodi Fukuda JP, de Santana WC. Analysis of goals in 2011 futsal league's games [in Portuguese]. Rev Bras Futsal Futebol. 2012;4(11):62-66.

15. Göral K. Analysis of Serbia UEFA Futsal Euro 2016 competitions in terms of some variables. J Educ Train Stud. 2018;6(10):1-6; doi: 10.11114/jets.v6i10.3343.

16. Pinheiro AM, Gonçalves LA, Paulilo VT, Fantato Rodrigues E, Borin JP. Analysis of the volume of game in futsal athletes of world championship [in Portuguese]. Corpoconsciência. 2017;20(3):50-56.

17. Petreça DR, Garcia MC, Petreça LE, Colvero S, Flores A. Scout analysis of the professional indoor soccer team in Catarinense championship [in Portuguese]. Rev Bras Futsal Futebol. 2017;9(34):265-272.

18. Ohmuro T, Iso Y, Tobita A, Hirose S, Ishizaki S, Sakaue K, et al. Physical match performance of Japanese top-level futsal players in different categories and playing positions. Biol Sport. 2020;37(4):359-365; doi: 10.5114/ biolsport.2020.96322.

19. LNF Stats. Available from: https://ligafutsal.com.br/ estatisticas/.

20. Coutinho D, Gonçalves B, Travassos B, Wong DP, Coutts AJ, Sampaio JE. Mental fatigue and spatial references impair soccer players' physical and tactical performances. Front Psychol. 2017;8:1645; doi: 10.3389/ fpsyg.2017.01645.

21. Van Cutsem J, Marcora S, De Pauw K, Bailey S, Meeusen R, Roelands B. The effects of mental fatigue on physical performance: a systematic review. Sports Med. 2017; 47(8):1569-1588; doi: 10.1007/s40279-016-0672-0.

22. Coutinho D, Gonçalves B, Wong DP, Travassos B, Coutts AJ, Sampaio J. Exploring the effects of mental and muscular fatigue in soccer players' performance. Hum Mov Sci. 2018;58:287-296; doi: 10.1016/j.humov.2018.03.004.

23. Lovell R, Barrett S, Portas M, Weston M. Re-examination of the post half-time reduction in soccer work-rate. J Sci Med Sport. 2013;16(3):250-254; doi: 10.1016/j. jsams.2012.06.004.

24. Greig M, Marchant D, Lovell R, Clough P, McNaughton L. A continuous mental task decreases the physiological response to soccer-specific intermittent exercise. Br J Sports Med. 2007;41(12):908-913; doi: 10.1136/bjsm. 2006.030387.

25. Bradley PS, Sheldon W, Wooster B, Olsen P, Boanas P, Krustrup P. High-intensity running in English FA Premier League soccer matches. J Sports Sci. 2009;27(2): 159-168; doi: 10.1080/02640410802512775.

26. Di Salvo V, Gregson W, Atkinson G, Tordoff P, Drust B. Analysis of high intensity activity in Premier League soccer. Int J Sports Med. 2009;30(3):205-212; doi: 10.1055/s-0028-1105950.

27. Szwarc A, Oszmaniec M. A model of the efficiency of goalkeepers' actions in futsal. Hum Mov. 2020;21(4): 44-53; doi: 10.5114/hm.2020.95990.

28. Pizarro D, Práxedes A, Travassos B, del Villar F, Moreno $\mathrm{A}$. The effects of a nonlinear pedagogy training 
program in the technical-tactical behaviour of youth futsal players. Int J Sports Sci Coach. 2019;14(1):15-23; doi: 10.1177/1747954118812072.

29. Brosch T, Scherer KR, Grandjean D, Sander D. The impact of emotion on perception, attention, memory, and decision-making. Swiss Med Wkly. 2013;143:w13786; doi: 10.4414/smw.2013.13786.

30. Russell M, West DJ, Harper LD, Cook CJ, Kilduff LP. Half-time strategies to enhance second-half performance in team-sports players: a review and recommendations. Sports Med. 2015;45(3):353-364; doi: 10.1007/s40279-014-0297-0.

31. Silva LM, Pereira Neiva H, Cardoso Marques M, Izquierdo M, Almeida Marinho D. Effects of warm-up, postwarm-up, and re-warm-up strategies on explosive efforts in team sports: a systematic review. Sports Med. 2018; 48(10):2285-2299; doi: 10.1007/s40279-018-0958-5.

32. McShane BB, Gal D, Gelman A, Robert C, Tackett JL. Abandon statistical significance. Am Stat. 2019; 73(Suppl. 1):235-245; doi: 10.1080/00031305.2018. 1527253.

33. Benjamin DJ, Berger JO, Johannesson M, Nosek BA, Wagenmakers E-J, Berk R, et al. Redefine statistical significance. Nat Hum Behav. 2018;2(1):6-10; doi: 10.1038/ s41562-017-0189-z.

34. Burnham KP, Anderson DR. Multimodel inference: understanding AIC and BIC in model selection. Sociol Methods Res. 2004;33(2):261-304; doi: 10.1177/0049 124104268644 . 